\title{
Higher Education Faculty Staff Members' Attitudes toward Students' Inclusion with High Incidence Disabilities in Saudi Arabia
}

\author{
Ameen Ali Alhaznawi ${ }^{1, *}$ \& Abdullah Saleh Alanazi ${ }^{2}$ \\ ${ }^{1}$ College of Education, Special Education Department, University of Jeddah, Saudi Arabia \\ ${ }^{2}$ College of Education, Special Education Department, University of Hail, Saudi Arabia \\ *Correspondence: College of Education, Special Education Department, University of Jeddah, Saudi Arabia. E-mail: \\ aalhaznawi@uj.edu.sa
}

Received: December 2, 2020

Accepted: January 8, $2021 \quad$ Online Published: February 16, 2021

doi:10.5430/wje.v11n1p51

URL: https://doi.org/10.5430/wje.v11n1p51

\begin{abstract}
The purpose of this study is to explore the attitudes of faculty members at higher education toward inclusion for students with high incidence disabilities in higher education. For the aim of this study, a sample of 247 higher education faculty members were therefore collected. Multiple linear regression was conducted for data analysis. Results have shown that university-type accommodation services, training, academic rank, and university region are statistically significant predictors of higher education faculty members' attitudes toward the inclusion for students with high incidence disabilities in higher education. Some recommendations are hence provided to help improve the inclusion of students with high incidence disabilities in higher education in Saudi Arabia.
\end{abstract}

Keywords: attitude, inclusion, faculty members, high incidence disabilities, Saudi Arabia

\section{Introduction}

Over the recent past, there has been a sporadic change in the national labor markets, which has increased the significance of having a post-secondary education so that one can compete in the labor market. It has been observed that students with specific disabilities often encounter limited access to post-secondary education programs, which are the result of poor unemployment results (Tomasello \& Brand, 2018). Being able to identify the specific needs of students with disabilities in succeeding through post-secondary programs appears to be one of the most fundamental aspects.

Intending to address this concern, the National Center for the Study of Post-Secondary Educational Supports at the University of Hawaii has done a national survey on support programs in post-secondary education. The review is composed of questions that relate to disability support and relevant institutions that support post-secondary education.

The ability to access post-secondary education, which then can help obtain a job, is the most significant privilege for individuals with disabilities, and this will also improve their living standards. The employment rate of people with disabilities should be developed with a strong positive relationship between education level and the rate of work. The significance of post-secondary education for proper quality employment and adequate living is exhibited in post-secondary education attendance (Tomasello \& Brand,2018).

Since 1973, the population of students living with disabilities as indicated has lapsed and also decreased, especially with cases of orthopedic disabilities. On the other hand, the number has increased in the case of students with learning disabilities in general. Learning disabilities compromise how information is received, synthesized, and expressed. The proper guidance that matches the instructions to abilities, working with students with learning disabilities with regards to these demands is a significant challenge for full post-secondary faculty administrators and assistant personnel.

By the end of the 1980s, only a simple scope of support and services had been made available to students who suffer from various disabilities in post-secondary education programs. Ten years later, there were numerous changes in the population of students suffering including multiple disabilities and for the complexities of the support they demand. 
Disability support officials often provide these services. As states consider the manner in which the number of youths, including college attendants and career ready, can be increased, there is a need to factor in the reality that students with disabilities can succeed. States can enhance career readiness by equipping students in skills and knowledge on their relevant work demands (Alqarni et al., 2019). This will support these students lead a successful lifestyle and have better employment opportunities.

Despite the significant efforts that have been made in improving career readiness for students who have various disabilities, there is still a need to scale up the efforts to enable more students to attain their full potential. Every Student Succeeds Act (ESSA) of 2015 offers states the ability to navigate over the design and structure of their own education systems and give extra provisions in order to improve college and career readiness for all students. The individuals with Disabilities Act (IDEA) offers protection to students who have different forms of disabilities so as to ensure that they are able to access free public education that is appropriate in the least restrictive environment.

According to Tomasello \& Brand (2018), the U.S. Department of Education considers students with disabilities as those who receive a kind of special education and other related services, as described under the IDEA. Students with disabilities who get to be served by IDEA include students with various intellectual deficiencies, hearing incapacity, speech impairment, visual impairment, orthopedic impairment, autism, and any other form of abnormalities. One in every five students in the U.S. has a particular learning issue (e.g., dyslexia or hyperactivity). According to Tomasello \& Brand (2018), the number of children between the ages of 3-21 getting special education under the IDEA is said to be approximately 6.6 million.

A study was conducted by Alqarni et al. (2019) regarding college students' knowledge and attitudes toward inclusion of people with disabilities at the university setting in Saudi Arabia. The study provided significant results that will aid both academics and social awareness of the disabled in higher education. The study recommended that students without disabilities need to be educated on how to handle other students with disabilities and on how to treat them better. Students with disabilities also need to be offered better accommodation and an environment that guarantees effective and comfortable learning.

Despite the progress that has been made so far in improving college and career readiness for students who have various disabilities, there is still a lot of work that needs to be done to ensure an increase in the number of students who complete high school, earn a college degree, and finally gain employment. Students with disabilities often graduate from high schools at a much lower rate when compared to the general population (Alqarni et al.,2019). In the 2014-15 school year, graduation rates from high schools were at 83\% in Saudi Arabia. This was an increase from $82 \%$ in the initial year. However, although there is an increase in the graduation rate from $64 \%$ to $65 \%$, a great gap remains between students who have disabilities and the general student population.

\section{Literature Review}

\subsection{Overview of the American Regulations for Students with Disabilities in Higher Education}

Throughout the history of unfair treatment of the disabled, the level of treatment has changed significantly across all societies and countries, with factors ranging from exclusion to denial. According to Worthy (2013), non-disabled individuals can display a number of negative reactions toward people with various kinds of disabilities. The research by Worthy (2013) focused on the attitude of the members of faculty toward students with multiple disabilities and how this is expected to contribute to their anxiety, sympathy, and poor attitude.

The National Council of Disability advises that both policy and curriculum changes should be enacted at the secondary level to support the Individuals with Disabilities. The full implementation of IDEA would guarantee that students suffering from a wide range of disabilities gain access to higher Education (Worthy, 2013). The National Department of Education, National Centre for Education Statistics, Individual with Disabilities Act, and many other laws, for instance, the Rehabilitation Act of 1973 and the Americans with Disabilities Act of 1990, guarantees equal access and benefits of education to persons with disabilities. Section 504 of the Rehabilitation is a human rights law that limits the discrimination and the unfair treatment of disabled people by programs that receive funding from the government (Scott, 2011).

To get more knowledge on whether higher education institutions must provide testing accommodations, testing firms that strictly follow Section 309 of the Americans with Disabilities Act of 1990 and adhere to Section 504 of the Rehabilitation Act of 1973 as it has been amended are needed on college and university campuses (Scott, 2011). Section 309 of the ADA gives a clear explanation that any individual, offering certain examination or courses related to the applications issuance of license, certification, or even giving credentials for secondary and post-secondary 
education, needs to provide students with disabilities, of all types, with an easily-accessible environment. Section 504 also prohibits the intentional discrimination against people with several of disabilities by institutions or even organizations that receive funding from the national government. People who require accommodations can only get them only when they are experiencing a particular disability as elaborated by these statutes (Scott, 2011). Both the ADA and the Rehabilitation Act clearly state that people with disabilities are those that have physical as well as a psychological impairment that might limit a few normal life activities.

In 2008, Congress put in place the ADA Amendments Act (ADAAA). By doing so, they rejected several Supreme Court interpretations that have defined an individual with disabilities. The ADA Amendments Act provides guidelines that determine who qualify as an individual with disabilities and also provides a number of activities to be benefited from.

The ADAAA was approved by the Congress in December 2008 and was put into effect in January 2009. The critical piece of legislation changed what Congress had initially considered being a negation from the initial intent of the initial ADA that brought in place several narrow interpretations of the novel law through the Supreme Court decisions (Parent Advocacy Brief, 2008). The ADAAA has had a significant effect on section 504 of the Rehabilitation Act of 1973. This Federal law was designed to secure the rights of persons with disabilities in programs and activities that receive federal financial help from the United States Department of Education. Because the recipients of the federal financial assistance include district public schools, institutions of higher learning, and many state and local education agencies, Section 4 is a significant law that provides and offers protection for children that attend school while battling multiple disabilities (Parent Advocacy Brief, 2008).

The Parents Advocacy Brief (2008) helps understanding the various changes that are provided by the ADAAA, its applications to Section 504, and how the changes affect children with several disabilities. These disabilities include learning cases such as Attention Deficit Hyperactive Disorder (ADHD), Asperser's Syndrome, diabetes, asthma, and food allergies.

\subsection{Impact of Faculty Attitudes towards Students with Disabilities in the Post-Secondary Setting}

A study by Wolstenholme (2010) explored the numerous ways inclusion has been seen and analyzed in context regarding students with personal care and different physical needs. The researcher put together the opinions of various faculty members in secondary schools and at colleges and universities. The findings of the study indicate that there are several variations in the manner in which people show their willingness toward the inclusion of students with disabilities and suggested that there is a need to offer greater consistency in the approach, particularly when certain desires of these students are not met. Wolstenholme (2010) agreed that there is a need to ensure that schools offer a proper environment that accommodates diversity, having assessed all the literature on factors associated with individual attitudes.

A study conducted by Murray et al. (2014) attempted to identify the impacts of intensive disability-focused training experience on university faculties' self-efficacy. The study evaluated the short-term pacts of training that is disability focused on the disability-related self-efficacy among the university faculty. Three diverse groups of faculties took part in a rampant 4-day training program aimed at trying to understand the college students living with different disabilities. Self-efficacy, when working with students having various disabilities, was measured and estimated before and after the training of faculty members. Participation in the training process by the faculty had a significant effect on the faculty's self-efficacy for trying to understand and helping students with disabilities.

According to a study conducted by Nolan et al. (2015), the number of students having disabilities and having access to higher education institutions has risen in the last 10 years in the Republic of Ireland. In one of the institutions of higher education in the Republic of Ireland, it was recorded that the number of disabled students able to attend learning increased from 67 as recorded in 2006 to 259 in 2013 on courses that were more technical.

The purpose of the Nolan et al. (2015) study was to identify the issues and the concerns raised by education practitioners in supporting students having various disabilities. A survey was conducted to meet the objectives of the study. The respondents involved 68 practitioners and 63 students having multiple disabilities. The practitioners were found to be concerned with students who had limited skills and how to support such them.

\subsection{Disability Support Services}

A study was done by Bakri (2019) that focused on reasonable accommodations for students suffering from various disabilities. In the past, in Saudi Arabia, students suffering from multiple disabilities often had only a small part in post-secondary education. The explosion in the numbers and population in recent years has presented a significant challenge at institutions of post-secondary education because of the need for a well-equipped collaboration between 
the faculty members and other staff. The law provides for post-secondary education institutions $t$ to offer full support to students suffering from various learning disabilities. The main objective of the study was to carry out a thorough analysis of the findings collected from three particular groups which were female faculty, female students with disabilities, and the center for disability services staff. A survey was conducted with several questions, and interviews were used in gathering their opinions.

The Bakri (2019) study observed that a faculty that managed to interact directly with students with learning disabilities are quite willing and very capable of offering accommodations. However, most of faculty felt that they did not have the required formal education to be able to meet the demands of the students within their classrooms. A significant deficiency was identified as well as the awareness of faculty members to be able to address the rights of students with learning disabilities. Another significant barrier that the study managed to identify was the existence of a communication gap between the members of the faculty as well as staff from the CDSS.

Strauss and Sales (2010) conducted a study on bridging the existing gap between disabilities studies as well as services in higher education. The results showed that the disabilities field in the area of higher education and disability studies have a shared commonality: it considers disability as being a socially constructed problem. Despite the existence of this similarity, there has been little effort to establish the ways in which disability services and studies maybe bridged. In the past, there have been significant efforts to improve the service quality deliverance to people suffering from various kinds of disabilities and taking part in higher education.

The Association of Higher Education and Disabilities has repeated the values as well as the mission in a manner the represents the disability as a social construct. The Association has also produced a code of ethics and standard of practice that consider the significance of restructuring the campus environments in a manner that is accessible to all as much as possible (Strauss \& Sales, 2010).

While previous studies have been done to discover teachers and families' attitudes toward the inclusion for students with disabilities in general, there is no information about inclusion for students with high incidence disabilities in higher education in Saudi Arabia.

\subsection{This Study Had the Following Research Questions}

R1: What are higher faculty members' attitudes toward Inclusion for students with high incidence disabilities in Saudi Arabia?

R2: To what extent do higher faculty members' gender, academic rank, university region, university type, accommodation services, and training explain higher faculty members' attitudes toward Inclusion for students with high incidence disabilities in Saudi Arabia.

\section{Method}

\subsection{Data and Sampling}

Quantitative research methodology has been used for the purpose of this study. A cross-sectional survey design has also been implemented to achieve the research objectives. This design would helpdivide the research questions by using a questionnaire survey in small sections to measure the main issue of this research, which in turn helped measure, analyze, and discuss the results.

\subsection{Instrumentation}

The survey instrument in this study has been developed to assess faculty members' attitudes toward Inclusion for students with high incidence disabilities in Saudi Arabia. The survey included an initial page of background information (research title, purpose of the study, statement of informed consent, estimated completion time, and participants' rights), including instructions on how to complete the survey. The survey questionnaire has two sections: (a) demographic information of the participants; and (b) attitudes items.

\subsection{Validity and Reliability}

The researchers conducted a pilot test with 18 faculty members in Saudi Arabia. The pilot test was used to look for initial evidence of the usefulness of the survey and to define the validity and reliability of the instrument. Feedback from all 18 faculty members were taken into consideration. As a result, items that had low reliability from the pilot test were canceled. Also, the instrument was mentioned during the literature review to determine the objectives of the measurement and support the survey validity. Three experts in quantitative research were invited to develop the validity of the survey. All comments and feedback from experts were considered. 


\subsection{Survey Distribution}

Researchers used the Qualtrics survey website to create and format the survey. The Qualtrics software allows the survey to be linked on the website and allows the researchers to organize information and collect data automatically. Moreover, the Qualtrics survey link was created and sent to the participants.

\subsection{Analysis}

Quantitative method of research has been used to analyze the data collected from the field. Statistical Package for the Social Sciences (SPSS) software was used to analyze the data. Frequencies and percentages were used in this study when appropriate, and then were displayed in tables. In addition, a multiple regression analysis was conducted to examine the extent to which variables predict faculty members' attitude toward the Inclusion for students with high incidence disabilities in university, Saudi Arabia.

Dummy coding was also used in this study for faculty member academic rank and university locations variables to represent them in statistical techniques. Faculty member academic rank was coded from 1 - $5(1=$ Teacher assistant, $2=$ Lecture, $3=$ Assistant professor, $4=$ Associate professor, $5=$ Full professor) and the reference group was the teacher assistant. University region was coded from 1 to $5(1=$ North region, $2=$ South region $3=$ East region, $4=$ West region, $5=$ Center region) and the reference group was north region.

\section{Results}

\subsection{Response Rate and Descriptive Results}

The Qualtrics platform was used in this study to collect data and answer this research questions, which is a commonly used data collection platform for researchers. Responses totaled 247 higher faculty members for 6 months of data collection.

\subsection{Gender}

The study sample consisted of 247 higher faculty members in Saudi Arabia, 170 (68.8\%) were male and 77 (31.2\%) of them were female higher faculty members.

\subsection{Years of Teaching Experience}

Each participant was asked to answer a question indicating their years of teaching through an open-ended text box. Participants' years of teaching experience in their careers ranged from 0 to 35 years with an average of 6 years' teaching experience. The data showed a wide variation in the years of teaching experience for survey respondents.

\subsection{Academic Rank}

The data showed that for the higher faculty members' rank, assistant professors were the most common educational role. $44(17.8 \%)$ participants were teachers assistant, 83 (33.6\%) were lecturers, $88(35.6 \%)$ were assistant professors, $20(8.1 \%)$ were associate professors, and only $12(4.9 \%)$ were full professors.

\subsection{University Region}

In the survey, participants had five options to indicate their universities regions. Participants were asked to choose from the following choices: north region, south region, east region, west region, and center region. Results indicated that $19(7.7 \%)$ were from the north region, $33(13.4 \%)$ were from the south region, $24(9.7 \%)$ were from the east region, $103(41.7 \%)$ were from the west region, and $68(27.5 \%)$ were from the center region (see Table 1$)$. The highest number of participants in this study $(41.7 \%)$ were from West region.

\subsection{University Type}

Responses showed that 170 (70\%) were from a Nascent University and 74 (30\%) were from non-Nascent university.

\subsection{Accommodation Services}

Participant were asked if their universities provide accommodation services for students with high incidence disabilities. Responses have shown that $101(40.9 \%)$ agreed that their university provides accommodation services for students with high incidence disabilities, and 146 (59.1\%) disagreed on the previous statement.

\subsection{Training}

Participants were asked if they had been trained on how to work with students with high incidence disabilities. Responses have shown that 107 (43.3\%) had this training, and $140(56.7 \%)$ had not had this training. 
Table 1. Demographics of the Study Participants

\begin{tabular}{|c|c|c|}
\hline \multirow[t]{2}{*}{ Item } & \multicolumn{2}{|l|}{$\mathrm{N}=247$} \\
\hline & Frequency & Percentage \\
\hline \multicolumn{3}{|l|}{ Gender } \\
\hline Male & 170 & $68.8 \%$ \\
\hline Female & 77 & $31.2 \%$ \\
\hline \multicolumn{3}{|l|}{ Academic Rank } \\
\hline Teacher Assistant & 44 & $17.8 \%$ \\
\hline Lecturer & 83 & $33.6 \%$ \\
\hline Assistant Professor & 88 & $35.6 \%$ \\
\hline Associate Professor & 20 & $8.1 \%$ \\
\hline Full Professor & 12 & $4.9 \%$ \\
\hline \multicolumn{3}{|l|}{ University Region } \\
\hline North Region & 19 & $7.7 \%$ \\
\hline South Region & 33 & $13.4 \%$ \\
\hline East Region & 24 & $9.7 \%$ \\
\hline West Region & 103 & $41.7 \%$ \\
\hline Central Region & 68 & $27.5 \%$ \\
\hline \multicolumn{3}{|l|}{ University Type } \\
\hline Nascent University & 173 & $70 \%$ \\
\hline Non-Nascent University & 74 & $30 \%$ \\
\hline \multicolumn{3}{|l|}{ Accommodation Services } \\
\hline Yes & 101 & $40.9 \%$ \\
\hline No & 146 & $59.1 \%$ \\
\hline \multicolumn{3}{|l|}{ Training Services } \\
\hline Yes & 107 & $43.3 \%$ \\
\hline No & 140 & $56.7 \%$ \\
\hline
\end{tabular}

\subsection{Reliability Estimates}

The survey items included positive items and one negative item. However, before analyzing the data, the researchers reversed the codes for the negative item's responses. The item anchor that had a response value of $7=$ "Strongly Disagree" was reversed to a value of 1 before the analyses and the item anchor "Strongly Agree" was assigned a value of 7. The regular positive items were left as they were in the survey. The negative item in the survey was item number 9. After running the reliability estimate for the surveys' items, researchers found that the coefficient alpha for the attitudes scale was .80 , which indicated a good reliability estimate based on the previously mentioned literature as shown in Table 2.

Table 2. Reliability Statistics of Higher Faculty Members' Attitudes

\begin{tabular}{ll}
\hline Survey Items & Cronbach's Alpha \\
\hline Teachers' Attitudes Alpha (9 Items) & .80 \\
\hline
\end{tabular}

\subsection{Research Question 1 Results}

To answer the first research question, "What are higher faculty members' attitudes toward Inclusion for students with high incidence disabilities in Saudi Arabia?" descriptive statistics were calculated for the highest and lowest mean of the items (items 3 and 5). The first scale's descriptive statistics measured higher education faculty members' attitudes about working with high incidence disabilities students requires extra effort (item 3). Table 3 shows the results. 
Table 3. Higher Education Faculty Members' Attitudes toward Inclusion for Students with High Incidence Disabilities

\begin{tabular}{|c|c|c|c|}
\hline & Item & $\mathrm{M}$ & $\mathrm{SD}$ \\
\hline 1 & Students with high incidence disabilities can study at the university successfully. & 1.83 & .89 \\
\hline 2 & $\begin{array}{l}\text { Student with high incidence disabilities have the ability to compete academically with their } \\
\text { peers at the university. }\end{array}$ & 1.87 & .95 \\
\hline 3 & Working with high incidence disabilities students requires extra effort. & 1.70 & .70 \\
\hline 4 & $\begin{array}{l}\text { Including students with high incidence disabilities requires more changes within } \\
\text { classrooms. }\end{array}$ & 2.01 & 1.08 \\
\hline 5 & $\begin{array}{l}\text { Excessive Attention to students with high incidence disabilities can negatively affect their } \\
\text { peers. }\end{array}$ & 3.20 & 1.32 \\
\hline 6 & Some faculty feels uncomfortable working with students with high incidence disabilities. & 2.50 & 1.19 \\
\hline 7 & I think that students with high incidence disabilities feel embarrassed about their disability. & 2.72 & 1.07 \\
\hline 8 & Students with high incidence disabilities show less enthusiasm than their peers & 3.10 & 1.22 \\
\hline 9 & Students with high incidence disabilities look for special treatment compared to their peers & 2.42 & 1.06 \\
\hline
\end{tabular}

The results indicated that higher education faculty members on average $(M=1.70, S D=6.99)$ have agreed that working with high incidence disabilities students requires extra effort. A majority of the participants $(221 ; 89.5 \%)$ both strongly agreed and agreed with the statement "Working with high incidence disabilities students requires extra effort." On the other hand, only $4(1.6 \%)$ of the participants indicated that they disagreed with the statement, "Working with high incidence disabilities students requires extra effort." Twenty-two (8.9\%) of the responded neither agreed nor disagreed.

The second item 5 measured if excessive attention to students with high incidence disabilities can negatively affect their peers. Participants showed that higher education faculty members on average $(M=3.20, S D=1.32)$ strongly disagreed and agreed that excessive attention to students with high incidence disabilities can negatively affect their peers. More than half of the participants $135(54.7 \%)$ strongly disagreed and disagreed that excessive attention to students with high incidence disabilities can negatively affect their peers. in contrast, 79 (32\%) of the participants strongly agreed and agreed that excessive attention to students with high incidence disabilities can negatively affect their peers. Thirty-three (13.4\%) of the participants neither agreed nor disagreed if excessive attention to students with high incidence disabilities can negatively affect their peers.

Table 4 shows the means of higher education faculty members' attitudes toward inclusion for students with high incidence disabilities in Saudi Arabia via demographic information. The mean score of male higher education faculty members' attitudes toward inclusion for students with high incidence disabilities was $(M=2.66 ; S D=.31)$, while females' mean score was $(M=2.57 ; S D=.27)$, which is lower than their male counterparts. Higher education faculty members with lecturer academic rank had the highest mean scores $(M=2.77 ; S D=.34)$ compared to other higher education faculty members' academic rank, and the lowest mean was for higher education faculty members with a teacher assistant $(M=2.55 ; S D=1.10)$.

The mean for higher education faculty members in the east region' attitudes was $(M=2.62 ; S D=.36)$, which was higher than other regions. Additionally, higher education faculty members who work in a non-nascent university had a higher mean $(M=2.68 ; S D=.31)$ compared to others who work in a nascent university $(M=2.57 ; S D=.28)$. Significantly, higher education faculty members who had received training showed positive attitudes toward inclusion for students with high incidence disabilities in universities. Their mean score was $(M=2.74 ; S D=.26)$, while others who did not have training showed low scores $(M=2.55 ; S D=.30)$.

Higher education faculty members who have more years of teaching experience showed high mean scores $(M=2.65$; $S D=.29$ ) toward inclusion for students with high incidence disabilities in universities, while others who have low teaching experience showed a low mean score $(M=2.61 ; S D=.31)$. Additionally, higher education faculty members who work in a university that does not provide accommodation services have positive attitudes toward inclusion for students with high incidence disabilities in universities and displayed a high mean score $(M=2.68 ; S D=.33)$ compared to those who work in university that provide accommodation services $(M=2.57 ; S D=.22)$. As a result, differences in the sample were assessed while controlling for other variables to see if they were meaningfully different in the regression analysis. 
Table 4. Higher Faculty Members’ Attitudes Scores for Demographic Information

\begin{tabular}{|c|c|c|c|}
\hline \multirow[t]{2}{*}{ Variables } & \multicolumn{3}{|c|}{ Behavior } \\
\hline & $N$ & $M$ & $S D$ \\
\hline \multicolumn{4}{|l|}{ Gender } \\
\hline Male & 170 & 2.66 & .31 \\
\hline Female & 77 & 2.57 & .27 \\
\hline \multicolumn{4}{|l|}{ Academic Rank } \\
\hline Teacher Assistant & 44 & 2.55 & .21 \\
\hline Lecturer & 83 & 2.77 & .34 \\
\hline Assistant Professor & 88 & 2.58 & .28 \\
\hline Associate Professor & 20 & 2.66 & .20 \\
\hline Full Professor & 12 & 2.63 & .08 \\
\hline \multicolumn{4}{|l|}{ University Region } \\
\hline North Region & 19 & 2.50 & .27 \\
\hline South Region & 33 & 2.58 & .15 \\
\hline East Region & 24 & 2.62 & .36 \\
\hline West Region & 103 & 2.61 & .31 \\
\hline Central Region & 68 & 2.74 & .29 \\
\hline \multicolumn{4}{|l|}{$\underline{\text { University Type }}$} \\
\hline Nascent University & 173 & 2.57 & .28 \\
\hline Non-Nascent University & 74 & 2.68 & .31 \\
\hline \multicolumn{4}{|l|}{ Accommodation Services } \\
\hline Yes & 101 & 2.57 & .22 \\
\hline No & 146 & 2.68 & .33 \\
\hline \multicolumn{4}{|c|}{ Years of Teaching Experience } \\
\hline Low Experience & 149 & 2.65 & .29 \\
\hline High Experience & 98 & .2 .61 & .31 \\
\hline \multicolumn{4}{|l|}{ Training } \\
\hline Yes & 107 & 2.74 & .26 \\
\hline No & 140 & 2.55 & .30 \\
\hline
\end{tabular}

Note: $(n=247)$.

\subsection{Regression Analysis Results}

Table 5. Regression Analysis of Higher Faculty Members' Attitudes toward Inclusion for Students with High Incidence Disabilities in Universities

\begin{tabular}{lrrrrr}
\hline & \multicolumn{2}{c}{ Unstandardized Coefficients } & \multicolumn{3}{c}{ Standardized Coefficients } \\
\cline { 2 - 6 } Category & \multicolumn{1}{c}{ Std. Error } & Beta & \multicolumn{1}{c}{ Sig. } & .230 \\
\hline Gender & -.049 & .041 & -.076 & -1.203 & .024 \\
University Type & -.109 & .048 & -.166 & -2.273 & .033 \\
Accommodation Services & .100 & .047 & .164 & 2.147 & .000 \\
Training & -.155 & .042 & -.255 & -3.726 & $<.000$ \\
Lecturer & .188 & .053 & .295 & 3.553 & .801 \\
Assistant Professor & -.013 & .052 & -.021 & -.253 & .220 \\
Associate Professor & .092 & .075 & .083 & 1.229 & .493 \\
Full Professor & -.069 & .101 & -.050 & -.686 & .184 \\
South Region & .109 & .082 & .124 & 1.333 & .001 \\
East Region & .280 & .083 & .275 & 3.377 & .120 \\
West Region & .119 & .077 & .195 & 1.560 & $<.000$ \\
Central Region & .406 & .079 & .601 & 5.161 & .074 \\
Years of Teaching Experience & .067 & .037 & .108 & 1.794 & \\
Note: $(n=247)$. & & & & & \\
\hline
\end{tabular}


Table 5 presents the results of the multiple regression analysis that reports a sizable proportion of total variation in higher education faculty members' attitudes toward inclusion of students with high incidence disabilities in universities.

Academic rank $(p<.001)$, university region $(p<.001)$, university type $(p<.02)$, accommodation services $(p=.03)$, and AT training $(p<.001)$ were statistically significant. Specifically, being a lecturer was associated with .19-unit greater positive attitude toward inclusion for students with high incidence disabilities in universities than others, controlling for other factors. Also, being a higher education faculty member in central university was associated with .40-unit greater positive attitude toward inclusion for students with high incidence disabilities in universities. Being a higher education faculty member in an east region university was associated with .28-unit greater reported positive attitudes toward inclusion for students with high incidence disabilities in universities, controlling for other factors. In addition, higher education faculty members who work at a nascent university were associated with .11-unit less reported positive attitudes toward inclusion for students with high incidence disabilities in universities.

Accommodation services was associated with .1-unit increase, which indicated that higher education faculty members who work at a university that provides accommodation services reported greater positive attitudes toward inclusion for students with high incidence disabilities in universities, controlling for other factors. Moreover, non-trained higher faculty members were associated with .15-unit less reported positive attitudes toward inclusion for students with high incidence disabilities in universities more than trained higher education faculty members.

\section{Discussion and Interpretation}

5.1 Research Question 1: What Are Higher Faculty Members' Attitudes Toward Inclusion for Students with High Incidence Disabilities in Saudi Arabia?

A majority of the participants in this study strongly agreed and agreed that working with high incidence disabilities students requires extra effort. Similarly, many studies have showed that the results of this study, higher education faculty members have a positive attitude towards inclusion for students with high incidence disabilities in Saudi Arabia, which in line with findings from Nolan et al. (2015) and Bakri (2019).

Most of the higher education faculty members in this study disagreed that excessive attention to students with high incidence disabilities can negatively affect their peers. This influences the quality of teaching by these higher education faculty members because it has been shown that excessive attention to students with high incidence disabilities will not negatively affect their peers. This study in line with Nolan et al. (2015) which found that 68 of the faculty members in the study were concerned with students who had a reaching standard of skill and how to support such students.

5.2 Research Question 2: To What Extent Do Gender, Academic Rank, University Region, University Type, Accommodation Services, and Training Explain Higher Faculty Members' Attitudes toward Inclusion for Students with High Incidence Disabilities in Saudi Arabia?

The results showed that university type, accommodation services, training, academic rank, and university region were statistically significant predictors of higher faculty members' attitudes toward inclusion for students with high incidence disabilities in Saudi Arabia. University type is a statistically significant predictor of higher faculty members' attitudes toward inclusion for students with high incidence disabilities for those who work at non-nascent university. These higher faculty members at the non-nascent university reported greater positive attitudes. This finding is supported in the literature in a study by Tomasello and Brand (2018).

This study revealed that higher faculty members who work at non-nascent university or institute. It was also determined that the higher faculty members who work at non-nascent university, which usually have a universal design for learning (an educational framework based on research that guides individualized learning) for people with disabilities, reported greater positive attitudes toward inclusion for students with high incidence disabilities.

Accommodation services was a significant predictor of higher education faculty members' attitudes toward inclusion for students with high incidence disabilities in higher education. The results show that higher education faculty members play a significant role in the implementation of interventions for students with high incidence disabilities in higher education based on their ability. These results are in line with Bakri (2019) who found that the majority of the faculty at both types of universities indicated that they would be willing to provide student with disability with virtually accommodation. 
Moreover, results in this study show that academic rank is a significant predictor of higher faculty members' attitudes toward inclusion for students with high incidence disabilities in higher education. Assistant professors play a significant role in the implementation of interventions for students with high incidence disabilities in higher education. Similarly, Abu-Hamour (2013) found that faculty members with an assistant professor rank have more positive attitudes toward inclusion of students with disabilities.

A university's region was a significant predictor of higher education faculty members' attitudes toward inclusion for students with high incidence disabilities. These results are in line with Grisham-Brown (1998) who also found that faculty members from rural areas of the state are concerned about having adequate faculty resources to teach courses to students with disabilities in these areas.

Training is a statistically significant predictor of higher faculty members' attitudes toward inclusion for students with high incidence disabilities in higher education. Higher education faculty members who have received training on how to teach people with high incidence disabilities reported more positive attitudes toward inclusion for students with high incidence disabilities in higher education. This is compatible with what has been reviewed in the literature, as Murray et al. (2014) reported that training has strong positive effects on faculty self-efficacy for understanding and supporting students with disabilities.

\section{Recommendations for Future Research}

The results of this study support the inclusion for students with high incidence disabilities in higher education based on the attitudes of higher education faculty members in Saudi Arabia. Moreover, these results are aligned with Abu-Hamour (2013) who reported that higher education faculty members have positive attitudes toward the inclusion for students with high incidence disabilities in higher education. Future research should explore the attitudes of stakeholders and decision makers in Ministry of Education toward the inclusion for students with high incidence disabilities in higher education. The information from this study could help create a training project for higher faculty members that would increase their skills of how to teach students with high incidence disabilities in higher education.

\section{Conclusion}

This study has revealed higher education faculty members' attitudes toward the Inclusion for students with high incidence disabilities in higher education. Based on these results, it is clear that higher education faculty members' attitudes toward the inclusion for students with high incidence disabilities in higher education depend on several factors, including training. Results of this study also show that university type, accommodation services, training, academic rank, and university region are statistically significant predictors of higher education faculty members' attitudes toward inclusion for students with high incidence disabilities in high education. Some recommendations have been provided to help improve the inclusion for students with high incidence disabilities in higher education in Saudi Arabia.

\section{References}

Abu-Hamour, B. (2013). Faculty attitudes toward students with disabilities in a public university in Jordan. International Education Studies, 6(12), 74-81. https://doi.org/10.5539/ies.v6n12p74

Alqarni, T., Algethami, R., Alsolmi, A., \& Adhabi, E. (2019). College students' knowledge and attitudes toward the inclusion of persons with disabilities in the university. Education, 9(1), 9-18.

Bakri, S. T. (2019). Reasonable accommodation for students with disabilities/learning disabilities: Perspectives of university faculty, staff, and students (Doctoral dissertation, Dissertation, Trinity College, Dublin Ireland). http://www.tara.tcd.ie/handle/2262/86885?show=full

Grisham-Brown, J., Knoll, J. A., Collins, B. C., \& Baird, C. M. (1998). Multi-university collaboration via distance learning to train rural special education teachers and related services personnel. Journal of Special Education Technology, 13(4), 110-121. https://doi.org/10.1177/016264349801300404

Murray, C., Lombardi, A., Seely, J. R., \& Gerdes, H. (2014). Effects of an intensive disability-focused training experience on university faculty self-efficacy. Journal of Postsecondary Education and Disability, 27(2), 179-193.

Nolan, C., Gleeson, C., Treanor, D., \& Madigan, S. (2015). Higher education students registered with disability 
services and practice educators: issues and concerns for professional placements. International Journal of Inclusive Education, 19(5), 487-502.

Parent Advocacy Brief (2008). Understanding the Americans with Disabilities and Amendments Act and Section 504 of the Rehabilitation Act. from https://www.ncld.org/wp-content/uploads/2014/11/Understanding-the-ADAAA-and-Section-504.pdf

Scott, G. A. (2011). Higher education and disability: improved federal enforcement needed to better protect students' rights to testing accommodations. Report to Congressional Requesters. GAO-12-40. US Government Accountability Office. Retrieved from https://www.gao.gov/products/GAO-12-40

Shaw, S. F., \& Dukes, L. L. (2001). Program standards for disability services in higher education. Journal of Postsecondary Education and Disability, 14(2), 81-90.

Strauss, A. L., \& Sales, A. (2010). Bridging the gap between disability studies and disability services in higher education: A model center on disability. Journal of Postsecondary Education and Disability, 23(1), 79-84.

Tomasello, J., \& Brand, B. (2018). How ESSA and IDEA can support college and career readiness for students with disabilities: Considerations for states. College and Career Readiness and Success Center. Retrieved from https://eric.ed.gov/?id=ED586419

Wolstenholme, C. (2010). Including students with personal care and physical needs: a discussion of how attitudes of school and college staff impact on effective educational inclusion. Support for Learning, 25(3), 146-150.

Worthy, K. L. (2013). Faculty attitudes toward students with disabilities at a southern HBCU. Retrieved from https://digitalscholarship.tnstate.edu/dissertations/AAI3587522/

\section{Copyrights}

Copyright for this article is retained by the author(s), with first publication rights granted to the journal.

This is an open-access article distributed under the terms and conditions of the Creative Commons Attribution license (http://creativecommons.org/licenses/by/4.0/). 